\title{
Pilihan Materi Pembelajaran Guru Pjok SMA dalam Memenuhi Tuntutan Kompetensi Dasar Kurikulum 2013
}

\author{
Muhammad Zaenudin Diharjo ${ }^{1 *}$, Lokananta Teguh Hari Wiguno ${ }^{2}$ \\ 1,2Jurusan Pendidikan Jasmani, Kesehatan dan Rekreasi, Fakultas IImu Keolahragaan, \\ Universitas Negeri Malang, Jalan Semarang No 5, Malang, Jawa Timur, 65145, Indonesia \\ *Penulis koresponden: mzaenudindiharjo@gmail.com,_081229024134
}

Artikel diterima: 27 Agustus 2020; direvisi: 10 Maret 2021; disetujui: 20 Maret 2021

\begin{abstract}
The purpose of this study was to determine the choice of learning materials for PJOK SMA teachers and what are the obstacles that occur in the learning process. This research uses surveyresearch method.. From the results of data analysis, it was found that the choice of learning materials for high school PJOK teachers in Purwosari District and Sukorejo District, Pasuruan Regency, got a grade Xpercentage of $37.40 \%$ which was in the unsuitable category and $45.45 \%$ for class XI was included in the inappropriate category. It can be concluded that the choice of learning materials for high school PJOK teachers in meeting the demands of basic competencies in the 2013 curriculum in Purwosari and Sukorejo districts for class Xis in the inappropriate category and for class $\mathrm{XI}$ is in the less appropriate category. This is influenced by several factors, namely: (1) facilities and infrastructure, (2) school regulations, (3) teacher competence.
\end{abstract}

Keyword: choice of material, teacher, basic competencies, curriculum 2013

\begin{abstract}
Abstrak:Tujuan penelitian ini adalah untuk mengetahui pilihan materi pembelajaran guru PJOK SMAdan apa saja hambatan yang terjadi dalam proses pembelajaran. Penelitian ini menggunakan metdoe penelitian survei.Darihasil analisis data, diperoleh hasil bahwa pilihan materi pembelajaran guru PJOK SMA di Kecamatan Purwosari dan Kecamatan Sukorejo Kabupaten Pasuruan mendapat persentase kelas Xsebesar 37,40\% ter masuk kategoritidak sesuai dan untuk kelas XI sebesar $45,45 \%$ termasuk dalam kategori kurang sesuai. Dapat diambil kesimpulan bahwa pilihan materi pembelajaran guru PJOK SMAdalam memenuhi tuntutan kompetensi dasar dalam kurikulum 2013 di Kecamatan Purwosari dan Kecamatan Sukorejo untuk kelas Xtermasuk dalam kategori tidak sesuai dan untuk kelas XI termasuk dalam kategori kurang sesuai. Hal ters ebut dipengaruhi beberapa faktor yaitu: (1) sarana dan prasarana, (2) peraturan sekolah, (3) kompetensi guru.
\end{abstract}

Kata kunci: pilihan materi, guru, kompetensi dasar, kurikulum 2013

\section{PENDAHULUAN}

Seiring berkembangnya zaman, pendidikan juga tak bisa lepas dari perkembangan zaman itu sendiri, pendidikan juga menjadi prioritas kebutuhan bagi umat manusia, seperti pengertiannya sendiri yaitu pendidikan merupakan proses pengubahan sikap dan perilaku seseorang atau sekelompok orang dalam upaya mendewasakan manusia melalui pengajaran dan pelatihan. Dari pengertiannya bisa diambil kesimpulan yaitu pendidikan memiliki peranan penting dalam banyak aspek kehidupan manusia. 
Didalam undang-undang nomor 20 tahun 2003 juga dijelaskan tentang fungsi pendidikan nasional, telah dijelaskan pada pasal 3 yaitu pendidikan nasional berfungsi untuk mengembangkan potensi dan membentuk watak serta peradaban bangsa dalam rangka mencerdaskan kehidupan bangsa, bertujuan untuk mengembangkan potensi peserta didik agar menjadi manusia yang seutuhnya yaitu manusia yang beriman dan bertakwa kepada Tuhan Yang Maha Esa, berakhlak, sehat jasmani dan rohani, berilmu, cakap, kreatif, mandiri, dan menjadi warga negara yang baik dan demokratis serta bertanggung jawab. Pendidikan sebagai usaha sadar yang sistematis-sistemik selalu bertolak dari sejumlah landasan serta mengindahkan sejumlah asa-asas tertentu. Landasan dan asas tersebut sangat penting, karena pendidikan merupakan pilar utama terhadap pengembangan manusia dan masyarakat suatu bangsa tertentu (Fernandes, Lynch, \& Netemeyer, 2014; Kroon et al., 2014).

Dalam pelaksanaan pendidikan kurikulum merupakan salah satu bagian terpenting dalam pengadaan pembelajaran disekolah, seperti pengertiannya sendiri kurikulum merupakan acuan pembelajaran dan pelatihan dalam pendidikan dan pelatihan. Oleh sebab itu, maka seorang guru harus melaksanakan pembelajaran mengacu kepada kurikulum. Kurikulum adalah seperangkat rencana dan pengaturan mengenai tujuan, isi dan bahan pelajaran serta cara yang dijadikan sebagai pedoman penyelenggaraan kegiatan pembelajaran untuk mencapai tujuan pendidikan tertentu. Maka dari itu kurikulum sangat diperlukan di lembaga pendidikan(Alsubaie, 2015; Cantoni, Chen, Yang, Yuchtman, \& Zhang, 2017; Mohanasundaram, 2018). Menurut dari beberapa sumber bahwa kurikulum adalah seperangkat dokumen yang berisikan ramburambu atau pedoman dalam menyusun perangkat pembelajaran untuk mencapai tujuan pendidikan tertentu. Kurikulum memiliki kaitan yang erat dengan pendidikan karena pada saat melakukan kegiatan belajar mengajar tentunya akan mengacu pada teori-teori dalam kurikulum. Kurikulum juga merupakan salah satu kebijakan pemerintah yang bertujuan untuk mengembangkan, mengevaluasi dan menyempurnakan program pembelajaran dalam semua jenjang pendidikan (Department for Education, 2013b, 2013a, 2015).

Didalam setiap jenjang pendidikan pasti memiliki standar kompetensi, kompetensi dasar dan indikator pencapaian. Tiga hal ini merupakan suatu hal yang saling berkaitan karena dari tiga hal tersebut kita dapat mengetahui tentang materi apa saja yang harus dipelajari dan tujuan apa saja yang harus dicapai. Dari standar kompetensi, kompetensi dasar dan indikator pencapaian kita bisa mengetahui kemampuan, keterampilan dan juga sikap peserta didik sehingga secara spesifik dapat dijadikan untuk menilai ketercapaian hasil pembelajaran dan juga menjadi sebuah tolak ukur sejauh mana siswa menguasai sebuah mata pelajaran. Kompetensi dasar merupakan pengetahuan, keterampilan dan sikap minimal yang harus dapat dicapai siswa untuk menjadi petunjuk bahwa siswa tersebut telah menguasai standar kompetensi yang telah ditetapkan dalam kurikulum.

Pendidikan jasmani olahraga dan kesehatan merupakan aktivitas pembelajaran melalui gerak yang dirangkai untuk meningkatkan kebugaran jasmani, perkembangan keterampilan dalam gerak, pengetahuan dan perilaku hidup sehat, aktif, mental yang kuat dan kestabilan emosi (Johnson, 2016; Pahor et al., 2014). Menurut Smith, Monnat, \& Lounsbery (2015) Pendidikan jasmani merupakan pendidikan yang mengaktualisasikan potensipotensi manusia berupa sikap, tindak dan karya dalam sebuah satu kesatuan utuh dalam diri manusia. Pendidikan jasmani olahraga dan kesehatan merupakan proses pendidikan yang melibatkan aktivitas kegiatan jasmani dan olahraga yang bertujuan untuk memberikan langkah bagi peserta didik dalam mengembangkan potensi maupun bakat yang dimiliki, sehingga dapat meningkatkan aspek sosial, mental, emosional, moral, fisik dan kebugaran jasmani dengan baik (Kwon \& Block, 2017; Smith et al., 2015).

Tujuan pendidikan jasmani, olahraga dan kesehatan adalah menciptakan siswa yang memiliki tubuh yang bugar melalui aktivitas fisik dan pola hidup sehat. Pendidikan jasmani, olahraga dan kesehatan juga bertujuan untuk meningkatkan kemampuan dan keterampilan yang berlandaskan sesuai dengan undang-undang RI no. 20 tahun 2003 pasal 3 tentang sistem pendidikan nasional yang berbunyi "bertujuan untuk berkembang nya potensi peserta didik agar menjadi manusia yang beriman dan bertakwa kepada Tuhan yang Maha Esa, berakhlak mulia, sehat, berilmu, cakap, kreatif, mandiri dan menjadi warga negara yang demokratis dan bertanggung jawab.

Pilihan materi guru dalam proses pembelajaran akan sangat berpengaruh terhadap tercapai atau tidaknya sebuah tujuan pendidikan nasional, apalagi di dalam mata pelajaran pendidikan jasmani yang memiliki tujuan sangat kompleks seperti yang telah dijelaskan di atas. Tentu saja guru PJOK harus menyajikan materi yang sesuai dengan apa yang sudah dirancang di dalam kurikulum, karena kurikulum merupakan pedoman untuk 
tercapainya tujuan pendidikan nasional. Guru memiliki peran penting dalam sistem pendidikan, sehingga seorang guru harus mempunyai kompetensi yang baik. Berdasarkan penelitian sebelumnya yang dilakukan oleh Rokim (2016) yang berjudul "Survei keterlaksanaan Kurikulum 2013 Pada Guru PJOK Di SMA Negeri Se Kabupaten Nganjuk" menyatakan bahwa tingkat pemahaman guru terhadap pelaksanaan pembelajaran mata pelajaran PJOK di dalam kurikulum 2013 dapat dikatakan dalam kategori paham.

Berdasarkan observasi awal yang telah dilakukan peneliti di Kecamatan Purwosari dan Kecamatan Sukorejo, pilihan materi pembelajaran guru PJOK SMA masih termasuk dalam kategori kurang sesuai pelaksanaannya dengan yang sudah dirancang dalam kurikulum. Hal ini dapat dilihat dari persentase yang di dapat dari hasil observasi yaitu untuk pilihan materi guru kelas X mendapat persentase 40,83\% termasuk dalam kategori kurang sesuai dan pilihan materi guru kelas XI mendapat persentase $46,25 \%$ termasuk dalam kategori kurang sesuai. Hal ini pun terjadi karena beberapa faktor diantaranya adalah sarana dan prasarana yang dimiliki sekolah kurang lengkap, kebijakan sekolah dalam mengatur proses pembelajaran dan kompetensi guru yang kurang baik atau kurangnya guru dalam penguasaan materi pembelajaran.

Berdasarkan latar belakang yang telah dipaparkan diatas, pentingnya penelitian ini dilakukan agar dapat mengetahui kualitas pembelajaran di sekolah yang dapat berguna bagi dinas pendidikan untuk terus meningkatkan kualitas pendidikan agar dapat mencapai tujuan pendidikan nasional. Maka penulis tertarik untuk melakukan penelitian dengan judul "Pilihan Materi Pembelajaran Guru PJOK SMA Dalam Memenuhi Tuntutan Kompetensi Dasar Dalam Kurikulum 2013 Di Kecamatan Purwosari dan Kecamatan Sukorejo".

\section{METODE}

Dalam penelitian ini, ditinjau dari sifat penelitian maka penelitian ini merupakan penelitian deskriptif kuantitatif. Metode yang digunakan adalah survei, teknik pengambilan data menggunakan kuesioner dan wawancara, skor yang diperoleh kemudian dianalisis menggunakan analisis deskriptif dan kuantitatif yang dituangkan dalam bentuk persentase.

Subjek yang diteliti pada penelitian ini adalah guru PJOK kelas X dan kelas XI di Kabupaten Pasuruan tepatnya di 7 sekolah yaitu SMAN 1 Purwosari, SMKN 1 Purwosari, SMA Darut Taqwa Purwosari, SMKN 1 Sukorejo, SMKN 2 Sukorejo, SMA Ma'arif Sukorejo dan MA Ma'arif Sukorejo. Penentuan sampel menggunakan teknik purposive sampling. Spesifikasi guru adalah guru kelas $\mathrm{X}$ dan kelas $\mathrm{XI}$.

Instrumen penelitian yang digunakan pada penelitian ini adalah instrumen non tes yaitu berupa kuesioner dan wawanca. Dalam penelitian menggunakan skala Guttman. Skala Guttman atau disebut juga analisis skalogram (scalogram analysis), menggunakan serangkaian penyataan yang terkait dengan suatu topik atau isu tertentu, dan kemudian disusun berdasar derajat intensitasnya (Morissan, 2012).

\section{Teknik Analisis Data}

Teknik analisis data pada penelitian ini menggunakan statistik deskriptif sederhana yaitu menghitung frekuensi dan persentase (Jamshed, 2014; Van Hoecke, 2016). Sedangkan rumus yang digunakan pada penelitian ini adalah:

$$
P=\frac{f}{N} \times 100 \%
$$

Keterangan:

$\mathrm{P}=$ Angka persentase

$f=$ Frekuensi yang sedang dicari persentase

$\mathrm{N}=$ Jumlah sampel

Untuk menentukan tercapainya pelaksanaan sebuah kurikulum dapat dilihat dalam tabel kriteria berikut: 
Tabel 1. Kriteria Penilaian Pelaksanaan Kurikulum (Kafle, 2013; Leguina, 2015)

\begin{tabular}{lll}
\hline No. & Rentangan Presentase & Kriteria \\
\hline 1 & $66 \%-100 \%$ & Sesuai \\
2 & $51 \%-65 \%$ & Cukup sesuai \\
3 & $41 \%-50 \%$ & Kurang sesuai \\
4 & $<-40 \%$ & Tidak sesuai \\
\hline
\end{tabular}

HASIL

Hasil pengolahan kuesioner kelas $\mathrm{X}$ sebagai berikut:

Tabel 2. Data Hasil Pilihan Materi Pembelajaran PJOK Kelas $X$

\begin{tabular}{lllll}
\hline No. & Komponen & Skor Hasil & Skor Maksimal & Persentase \\
\hline 1. & Permainan Bola Besar & 22 & 35 & $62.9 \%$ \\
2. & Permaianan Bola Kecil & 15 & 49 & $30.6 \%$ \\
3. & Atletik & 25 & 56 & $44.6 \%$ \\
4. & Beladiri & 7 & 56 & $12.5 \%$ \\
5. & Aktivitas Kebugaran Jasmani & 8 & 14 & $57.14 \%$ \\
6. & Aktivitas Senam Ketangkasan & 25 & 56 & $44.64 \%$ \\
7. & Aktivitas Senam Ritmik & 5 & 28 & $17.86 \%$ \\
8. & Aktivitas Air & 5 & 42 & $11.90 \%$ \\
9. & Pola Hidup Sehat & 17 & 28 & $60.71 \%$ \\
10. & Narkoba & 15 & 21 & $71.43 \%$ \\
\hline Jumlah & 144 & 385 & $37.40 \%$ \\
\hline
\end{tabular}

Dari hasil pengolahan data pada pilihan materi guru kelas $\mathrm{X}$, permainan bola besar memperoleh skor hasil 22 dan skor maksimal 35 dengan hasil persentase $62,9 \%$, permainan bola kecil memperoleh skor hasil 15 dan skor maksimal 49 dengan hasil persentase 30,6\%, atletik memperoleh skor hasil 25 dan sk or maksimal 56 dengan hasil persentase $44,6 \%$, beladiri memperoleh skor hasil 7 dan skor maksimal 56 dengan hasil persentase $12,5 \%$, aktivitas kebugaran jasmani memperoleh skor hasil 8 dan skor maksimal 14 dengan hasil persentase $57,14 \%$, aktivitas senam ketangkasan memperoleh skor hasil 25 dan skor maksimal 56 dengan hasil persentase $44,64 \%$, aktivitas senam ritmik memperoleh skor hasil 5 dan skor maksimal 28 dengan hasil persentase $17,86 \%$, aktivitas air memperoleh skor 5 dan skor maksimal 42 dengan hasil pers entase $11,90 \%$, pola hidup sehat memperoleh skor 17 dan skor maksimal 28 dengan hasil persentase $60,71 \%$, narkoba memperoleh skor 15 dan skor maksimal 21 dengan hasil persentase $71,43 \%$.

Berikut adalah grafik ilustrasi hasil persentase pilihan materi guru PJOK kelas $X$ : 


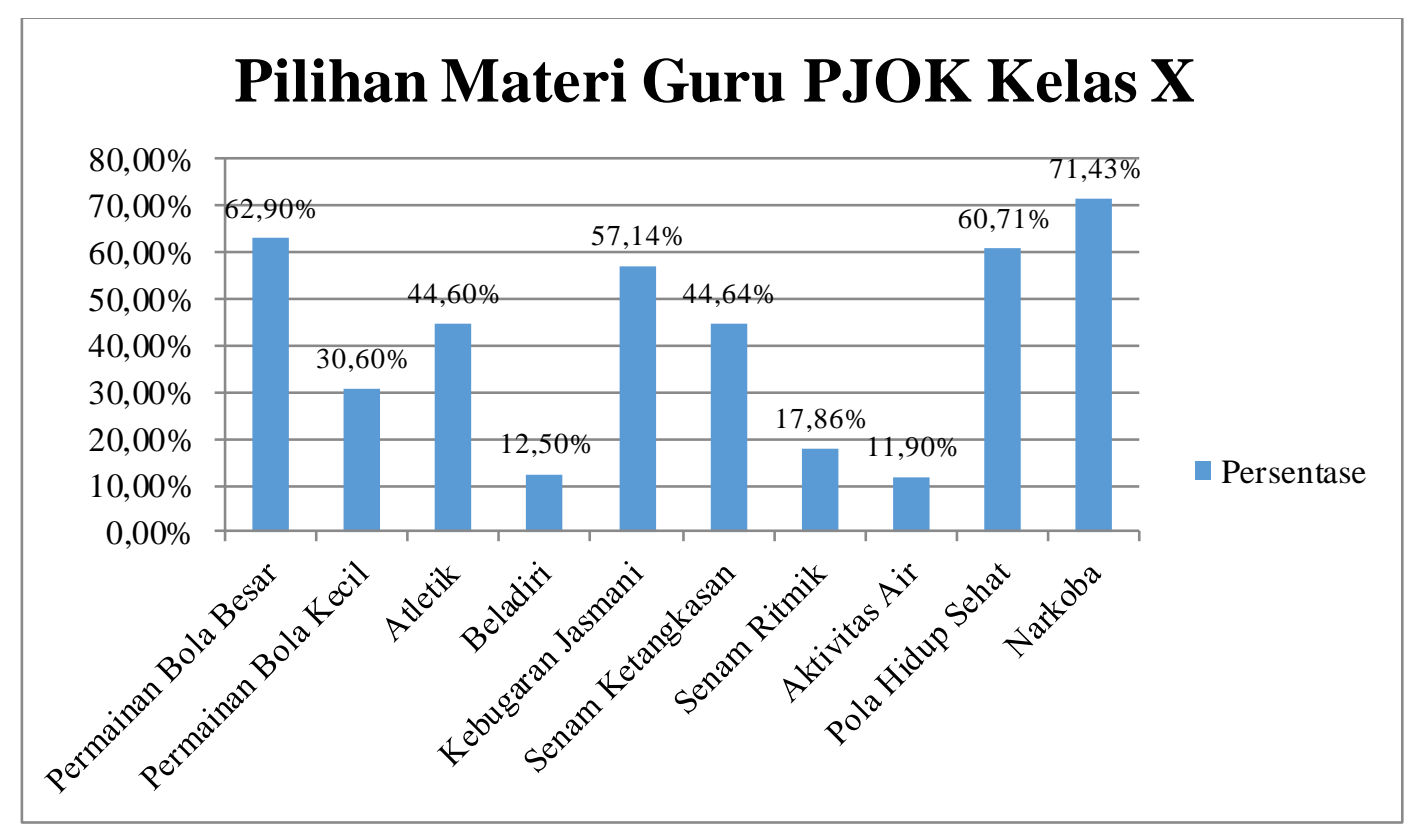

Gambar 1. Diagram Batang Hasil Persentase Pilihan Materi Guru PJOK Kelas X

Dari pengolahan data keseluruhan, maka diperoleh skor hasil 144 dan skor maksimal 385 dan diperoleh hasil persentase keseluruhan $37,40 \%$. Hasil pengolahannya sebagai berikut:

$$
\begin{array}{r}
P=\frac{f}{N} \times 100 \%=\frac{144}{385} \times 100 \% \\
=37,40 \%
\end{array}
$$

Hasil pengolahan kuesioner kelas XI sebagai berikut:

Tabel 3. Data Hasil Pilihan Materi Pembelajaran PJOK Kelas XI

\begin{tabular}{lllll}
\hline No. & Komponen & Skor Hasil & Skor Maksimal & Persentase \\
\hline 1. & Permainan Bola Besar & 24 & 35 & $68.57 \%$ \\
2. & Permaianan Bola Kecil & 21 & 49 & $42.86 \%$ \\
3. & Atletik & 30 & 56 & $53.57 \%$ \\
4. & Beladiri & 7 & 56 & $12.50 \%$ \\
5. & Aktivitas Kebugaran Jasmani & 9 & 14 & $64.29 \%$ \\
6. & Aktivitas Senam Ketangkasan & 34 & 56 & $60.71 \%$ \\
7. & Aktivitas Senam Ritmik & 10 & 28 & $35.71 \%$ \\
8. & Aktivitas Air & 5 & 42 & $11.90 \%$ \\
9. & Pola Hidup Sehat & 22 & 28 & $78.57 \%$ \\
10. & HIV/AIDS & 13 & 21 & $61.90 \%$ \\
\hline Jumlah & 175 & 385 & $45.45 \%$ \\
\hline
\end{tabular}

Dari hasil pengolahan data pada pilihan materi guru kelas XI, permainan bola besar memperoleh skor hasil 25 dan skor maksimal 35 dengan hasil persentase $68,57 \%$, permainan bola kecil memperoleh skor hasil 21 dan skor maksimal 49 dengan hasil persentase $42,86 \%$, atletik memperoleh skor hasil 30 dan skor maksimal 56 dengan hasil persentase 53,57\%, beladiri memperoleh skor hasil 7 dan skor maksimal 56 dengan hasil persentase $12,5 \%$, aktivitas kebugaran jasmani memperoleh skor hasil 9 dan skor maksimal 14 dengan hasil persentase $64,29 \%$, aktivitas senam ketangkasan memperoleh skor hasil 34 dan skor maksimal 56 dengan hasil persentase $60,71 \%$, aktivitas senam ritmik memperoleh skor hasil 10 dan skor maksimal 28 dengan hasil persentase 35,71\%, aktivitas air memperoleh skor 5 dan skor maksimal 42 dengan hasil persentase 11,90\%, pola hidup sehat memperoleh skor 22 dan skor maksimal 28 dengan hasil persentase $78,57 \%$, HIV/AIDS memperoleh skor 13 dan skor maksimal 21 dengan hasil persentase $61,90 \%$.

Berikut adalah grafik ilustrasi hasil persentase pilihan materi guru PJOK kelas XI: 


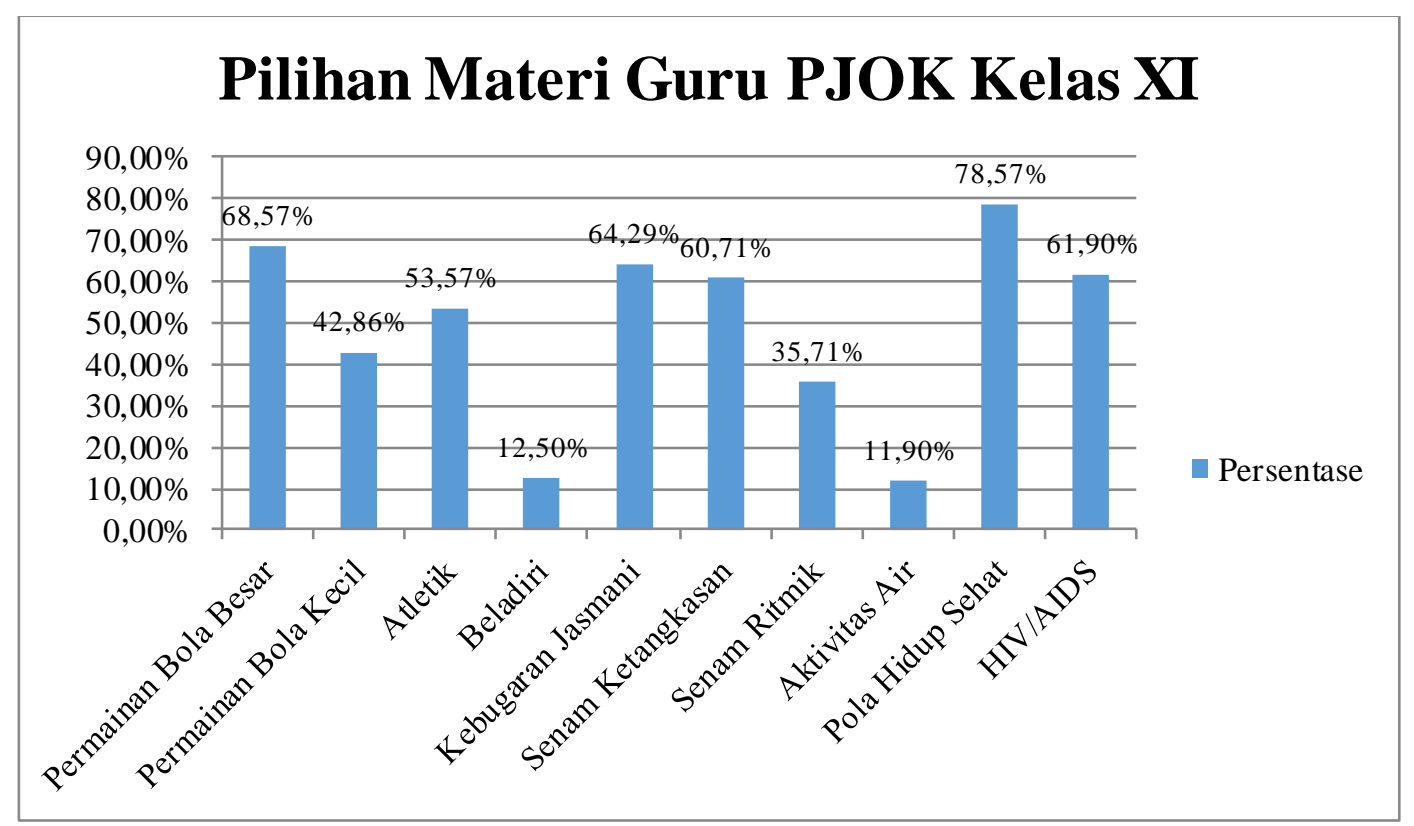

Gambar 2. Diagram Batang Hasil Persentase Pilihan Materi Guru PJOK Kelas XI

Dari pengolahan data keseluruhan, maka diperoleh skor hasil 175 dan skor maksimal 385 dan diperoleh hasil persentase keseluruhan $45,45 \%$. Hasil pengolahannya sebagai berikut:

$$
\begin{array}{r}
P=\frac{f}{N} \times 100 \%=\frac{175}{385} \times 100 \% \\
=45,45 \%
\end{array}
$$

\section{PEMBAHASAN}

Dari hasil data pilihan materi guru PJOK kelas $X$ dan kelas XI dapat diketahui ada beberapa hal yang mempengaruhi guru dalam menentukan pilihan materi pembelajaran yaitu sarana dan prasarana, kompetensi guru dan peraturan sekolah. Untuk sarana dan prasarana masih banyak sekolah yang kurang lengkap, padahal sarana dan prasarana sangat penting dalam menunjang pelaksanaan proses pembelajaran, hal itu sejalan dengan pendapat bahwa dengan keterbatasan sarana dan prasarana sekolah sudah tentu mempengaruhi hasil belajar siswa. Dengan kata lain proses pelaksanaan pendidikan di sekolah dan permasalahan pembelajaran bukan hanya dihadapi oleh guru yang bersangkutan, tetapi didukung pula oleh keberadaan dan kelengkapan sarana dan prasarana pendidikan (Adi \& Fathoni, 2019, 2020a, 2020c, 2020b; Fathoni, 2018). Ada juga pendapat dari Darmawan (2014) sarana dan prasarana yang memadai akan meningkatkan kualitas pendidikan dan olahraga. Sejalan dengan pendapat sebelumnya bahwa sarana dan prasarana merupakan salah satu penunjang yang penting dalam melakukan proses pembelajaran disekolah (Ratnasari, Sugiarto, \& Fitriady, 2020; Saputro, Kurniawan, \& Yudasmara, 2017). Di dalam temuan penelitian masih banyak sekolah yang memiliki sarana dan prasarana yang kurang, contohnya saja di SMKN 1 Sukorejo dan SMA Ma'arif Sukorejo tidak memiliki matras untuk senam ketangkasan sehingga pembelajaran tidak dilaksanakan. Untuk materi atletik yang membutuhkan alat seperti lempar lembing dan tolak peluru hampir semua sekolah masih kurang dalam jumlah sarana dan prasarananya sehingga proses pembelajaran kurang efektif.

Kompetensi guru juga berpengaruh terhadap pilihan materi pembelajaran, hal itu sejalan dengan pendapat bahwa kinerja guru dalam proses belajar mengajar (PBM) menjadi salah satu bagian terpenting dalam mendukung terciptanya proses pendidikan secara efektif terutama dalam membangun sikap disipl in dan mutu hasil belajar siswa (Biesta, Priestley, \& Robinson, 2015; Vangrieken, Dochy, Raes, \& Kyndt, 2015). Adapun penjelasan bahwa kompetensi yang dimiliki oleh setiap guru menunjukkan kualitas guru dalam melakukan pembelajaran, kompetensi tersebut dimulai dari bagaimana kemampuan guru untuk menyusun program perencanaan pembelajaran dan melaksanakan rencana pembelajaran tersebut (Feng \& Sass, 2017; Kim, Kim, Lee, Spector, \& DeMeester, 2013). Di dalam temuan penelitian ditemukan beberapa guru yang kurang kompeten dalam memberikan materi pembelajaran, contohnya saja pada KD Beladiri semua guru hanya 
memberikan materi pencak silat dan ada juga yang hanya memberikan sebatas materi tanpa praktik, guru lebih mengandalkan kegiatan ini melalui kegiatan ekstrakurikuler.

Peraturan sekolah juga mempengaruhi pilihan materi guru dalam pelaksanaan pembelajaran, hal ini terjadi di sekolah yang berbasis madrasah yang menganut sistem manajemen berbasis sekolah. Sejalan dengan pendapat Caldwell (2015) di dalam sistem manajemen berbasis sekolah semua kebijakan dan program sekolah ditetapkan oleh komite sekolah berdasarkan musyawarah dari para anggota yang terdiri dari pejabat pendidikan daerah, kepala sekolah, guru-guru, perwakilan orangtua siswa, tokoh masyarakat, dan pejabat daerah di mana sekolah itu berada. Adapun pendapat dari beberapa sumber menyatakan bahwa dalam menerapkan manajemen berbasis sekolah, maka pihak sekolah memiliki hak otonomi yaitu hak atau kewenangan sekolah dalam mengatur dan mengurus kepentingan sekolah dalam mencapai tujuan pendidikan serta dapat menciptakan mutu pendidikan yang baik (Azha et al., 2013; Fife, 2019; Vanevenhoven \& Liguori, 2013). Adapun pendapat dari Amanchukwu, Stanley, \& Ololube (2015) menyatakan bahwa dalam sistem manajemen berbasis sekolah, sekolah memiliki full authority and responsibility dalam menetapkan programprogram pendidikan dan berbagai kebijakan sesuai dengan tujuan pendidikan. Perlu dipahami bahwa semua kebijakan dan program sekolah ditetapkan oleh komite sekolah dan dewan pendidikan yang dibentuk berdasarkan musyawarah dari pejabat daerah, kepala sekolah, tenaga kependidikan, perwakilan orang tua peserta didik, dan tokoh masyarakat. Di dalam temuan penelitian, peraturan sekolah mempengaruhi pilihan materi guru dalam proses pembelajaran, contohnya saja di MA Ma'arif Sukorejo, SMA Ma'arif Sukorejo dan SMA Darut Taqwa Purwosari yang termasuk sekolah berbasis madrasah ataupun masih kental dengan unsur agama islam, guru PJOK tidak diperbolehkan untuk memberikan materi aktivitas air karena khawatir dengan situasi dan kondisi anak remaja zaman sekarang, karena itu juga akan berpengaruh terhadap nama lembaga.

\section{KESIMPULAN}

Kelompok materi permainan bola besar kelas $\mathrm{X}$ disimpulkan bahwa pilihan materi pembelajaran PJOK SMA kelas $X$ termasuk dalam kategori tidak sesuai. Beberapa faktor penyebabnya antara lain adalah kurang lengkapnya sarana dan prasarana yang ada di sekolah, kompetensi guru dalam penguasaan materi dan mengembangkan atau memodifikasi permainan dan faktor peraturan sekolah atau kebijakan-kebijakan khusus contohnya di sekolah yang berbasis madrasah. Kelompok materi permainan bola besar kelas XI disimpulkan bahwa pilihan materi pembelajaran PJOK SMA kelas XI termasuk dalam kategori kurang sesuai. Beberapa faktor penyebabnya antara lain adalah kurang lengkapnya sarana dan prasarana yang ada di sekolah, kompetensi guru dalam penguasaan materi dan mengembangkan atau memodifikasi permainan dan faktor peraturan sekolah atau kebijakan-kebijakan khusus contohnya di sekolah yang berbasis madrasah.

\section{DAFTAR PUSTAKA}

Adi, S., \& Fathoni, A. F. (2019). Development of Learning Model Based on Blended Learning in Sports School. https://doi.org/10.2991/acpes-19.2019.2

Adi, S., \& Fathoni, A. F. (2020a). Blended Learning Analysis for Sports Schools in Indonesia. International Journal of Interactive Mobile Technologies (IJIM), 14(12), 149-164. Retrieved from https://www.onlinejournals.org/index.php/i-jim/index

Adi, S., \& Fathoni, A. F. (2020b). Mobile Learning sebagai Fasilitas Belajar Mandiri Pembelajaran Senam Lantai pada Mahasiswa Jurusan IImu Keolahragaan. Jurnal Pendidikan: Teori, Penelitian, Dan $\begin{array}{llll}\text { Pengembangan, } & \text { 5(8), } & \text { Retrieved } & \end{array}$ http://journal.um.ac.id/index.php/jptpp/article/view/13946/6206

Adi, S., \& Fathoni, A. F. (2020c). The effectiveness and efficiency of blended learning at sport schools in Indonesia. International Journal of Innovation, Creativity and Change.

Alsubaie, M. A. (2015). Hidden curriculum as one of current issue of curriculum. Journal of Education and Practice.

Amanchukwu, R. N., Stanley, G. J., \& Ololube, N. P. (2015). A Review of Leadership Theories, Principles and Styles and Their Relevance to Educational Management. Management. 
https://doi.org/10.5923/j.mm.20150501.02

Azha, L., Baharuddin, S., Sayurno, Salahuddin, S. S., Afandi, M. R., \& H., H. A. (2013). The Practice and Management of Waqf Education in Malaysia. Procedia - Social and Behavioral Sciences. https://doi.org/10.1016/j.sbspro.2013.07.061

Biesta, G., Priestley, M., \& Robinson, S. (2015). The role of beliefs in teacher agency. Teachers and Teaching: Theory and Practice. https://doi.org/10.1080/13540602.2015.1044325

Caldwell, B. J. (2015). School Management. In International Encyclopedia of the Social \& Behavioral Sciences: Second Edition. https://doi.org/10.1016/B978-0-08-097086-8.92069-5

Cantoni, D., Chen, Y., Yang, D. Y., Yuchtman, N., \& Zhang, Y. J. (2017). Curriculum and ideology. Journal of Political Economy. https://doi.org/10.1086/690951

Darmawan, B. (2014). Manajemen Sarana dan Prasarana Dalam Meningkatkan Kualitas Pendidikan. Jurnal Pelopor Pendidikan.

Department for Education. (2013a). National curriculum in England: computing programmes of study. National Curriculum in England.

Department for Education. (2013b). Science programmes of study: key stage 3. National Curriculum.

Department for Education. (2015). National curriculum in England: science programmes of study. Statutory Guidance.

Fathoni, A. F. (2018). The Role of Blended Learning on Cognitive Step in Education of Sport Teaching by Adjusting the Learning Style of the Students. https://doi.org/10.2991/isphe-18.2018.49

Feng, L., \& Sass, T. R. (2017). Teacher quality and teacher mobility. Education Finance and Policy. https://doi.org/10.1162/EDFP_a_00214

Fernandes, D., Lynch, J. G., \& Netemeyer, R. G. (2014). Financial literacy, financial education, and downstream financial behaviors. Management Science. https://doi.org/10.1287/mnsc.2013.1849

Fife, P. (2019). Management Education. American Journal of Nursing. https://doi.org/10.1097/01.NAJ.0000569356.58153.e5

Jamshed, S. (2014). Qualitative research method-interviewing and observation. Journal of Basic and Clinical Pharmacy. https://doi.org/10.4103/0976-0105.141942

Johnson, M. (2016). Adapted Physical Education and Sport. Adapted Physical Activity Quarterly. https://doi.org/10.1123/apaq.28.4.368

Kafle, N. P. (2013). Hermeneutic phenomenological research method simplified. Bodhi: An Interdisciplinary Journal. https://doi.org/10.3126/bodhi. v5i1.8053

Kim, C. M., Kim, M. K., Lee, C. J., Spector, J. M., \& DeMeester, K. (2013). Teacher beliefs and technology integration. Teaching and Teacher Education. https://doi.org/10.1016/j.tate.2012.08.005

Kroon, F. P., van der Burg, L. R., Buchbinder, R., Osborne, R. H., Johnston, R. V., \& Pitt, V. (2014). Selfmanagement education programmes for osteoarthritis. Cochrane Database of Systematic Reviews. https://doi.org/10.1002/14651858.CD008963.pub2

Kwon, E. H., \& Block, M. E. (2017). Implementing the adapted physical education E-learning program into physical education teacher education program. Research in Developmental Disabilities. https://doi.org/10.1016/j.ridd.2017.07.001

Leguina, A. (2015). A primer on partial least squares structural equation modeling (PLS-SEM). International Journal of Research \& Method in Education. https://doi.org/10.1080/1743727x.2015.1005806

Mohanasundaram, K. (2018). Curriculum Design and Development. Journal of Applied and Advanced Research. https://doi.org/10.21839/jaar.2018.v3is1.156

Pahor, M., Guralnik, J. M., Ambrosius, W. T., Blair, S., Bonds, D. E., Church, T. S., ... Williamson, J. D. (2014). Effect of structured physical activity on prevention of major mobility disability in older adults: The LIFE 
study randomized clinical trial. JAMA - Journal of the American Medical Association. https://doi.org/10.1001/jama.2014.5616

Ratnasari, E. D., Sugiarto, T., \& Fitriady, G. (2020). Survei Sarana dan Prasarana Mata Pelajaran Pendidikan Jasmani Olahraga dan Kesehatan Tingkat SMP. Sport Science and Health, 2(11), 534-542. Retrieved from http://journal2.um.ac.id/index.php/jik/index

Rokim, Moh. 2016. "Survei keterlaksanaan Kurikulum 2013 Pada Guru PJOK Di SMA Negeri Se Kabupaten Nganjuk." Unesa University Press 4.

Saputro, T., Kurniawan, A. W., \& Yudasmara, D. S. (2017). Survei Sarana dan Prasarana Pendidikan Jasmani dan Olahraga. Sport Science and Health, 2(20), 456-463. Retrieved from http://journal2.um.ac.id/index.php/jfik/index

Smith, N. J., Monnat, S. M., \& Lounsbery, M. A. F. (2015). Physical Activity in Physical Education: Are Longer Lessons Better? Journal of School Health. https://doi.org/10.1111/josh.12233

Van Hoecke, M. (2016). Methodology of Comparative Legal Research. Law and Method. https://doi.org/10.5553/rem/.000010

Vanevenhoven, J., \& Liguori, E. (2013). The impact of entrepreneurship education: Introducing the entrepreneurship education project. Journal of Small Business Management. https://doi.org/10.1111/jsbm.12026

Vangrieken, K., Dochy, F., Raes, E., \& Kyndt, E. (2015). Teacher collaboration: A systematic review. Educational Research Review. https://doi.org/10.1016/j.edurev.2015.04.002 